\title{
Dinâmica da agroindústria familiar: estratégia de reprodução social e econômica da agricultura familiar ${ }^{1}$
}

\section{Family agroindustry as a family farming reproduction strategy}

\author{
Fabíola Graciele Besen* \\ Clério Plein ${ }^{\star \star}$ \\ Marcos Andrade ${ }^{\star \star *}$
}

\begin{abstract}
Resumo: O objetivo do artigo é identificar de que forma a agroindústria familiar contribui como estratégia de reprodução e fortalecimento da agricultura familiar. $\mathrm{O}$ delineamento da pesquisa se constituiu pela pesquisa bibliográfica. Identificou-se que a agroindústria familiar passa a gerar renda e trabalho para os componentes familiares, proporcionando sustentabilidade socioeconômica. Em relação a comercialização, criam o mercado para seus produtos em nível local utilizando-se dos laços sociais, de amizade e de parentesco. Também proporcionam a valorização e preservação dos hábitos culturais, estímulo da proximidade social (produtor-consumidor) e valorização das especificidades locais. A agroindústria pode ser considerada um contramovimento da agricultura familiar na busca por sobrevivência centrada em outras formas de relações econômicas mais justas e coerentes para produtores e consumidores, se firmando como uma estratégia de reprodução e fortalecimento da agricultura familiar.
\end{abstract}

Palavras-chave: Agricultura familiar. Agroindústria. Desenvolvimento rural.

Abstract: The aim of the article is to identify how the family agroindustry contributes as a strategy for the reproduction and strengthening of family

\footnotetext{
${ }^{1}$ Uma versão preliminar deste texto foi apresentada no "II SEMINÁRIO INTERNACIONAL DE PÓS-GRADUAÇÃO EM DESENVOLVIMENTO RURAL SUSTENTÁVEL" em Foz do Iguaçu, entre 07 a 09 de agosto de 2019, sendo indicado pelo evento para compor este volume especial.

*Doutoranda em Desenvolvimento Rural Sustentável pela Universidade Estadual do Oeste do Paraná (Unioeste); Mestra em Desenvolvimento Rural Sustentável pela Unioeste; Graduada em Ciências Contábeis pela Unioeste; Graduada em Letras Português pela Unioeste; Professora da Unioeste. E-mail: fabiolagracielebesen@gmail.com.

${ }^{* *}$ Doutor em Desenvolvimento Rural pela Universidade Federal do Rio Grande do Sul (UFRGS); Mestre em Desenvolvimento Rural pela UFRGS; Graduado em Economia Doméstica pela Universidade Estadual do Oeste do Paraná (Unioeste); Professor da Unioeste. E-mail: clerioplein@gmail.com.

**** Doutorando em Desenvolvimento Rural Sustentável pela Universidade Estadual do Oeste do Paraná (Unioeste); Mestre em Desenvolvimento Rural Sustentável pela Unioeste; Graduado em Direito pela Faculdade Unificada de Foz do Iguaçu (UNIFOZ); Graduado em Ciências Contábeis pela Unioeste. Professor da Unioeste. E-mail: marcos.consultor@hotmail.com.
}

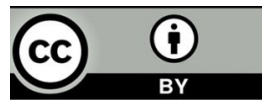


agriculture. The research design consisted of bibliographical research. It was identified that the family agro-industry starts to generate income and work for the familiar components, providing socioeconomic sustainability. In relation to marketing, they create the market for their products at the local level using social, friendship and relatives ties. They also provide the valuation and preservation of cultural habits, stimulation of social proximity (producer-consumer) and appreciation of local specificities. Agribusiness can be considered a countermovement of family agriculture in the quest for survival centered on other forms of economic relations more just and coherent for producers and consumers, being established as a strategy of reproduction and strengthening of family agriculture.

Keywords: Family farming. Agroindustry. Rural development.

Recebido em 06/11/2019. Aceito em 11/03/2020.

\section{Introdução}

O processo chamado Revolução Verde, iniciado na década de 50, em que implementou-se um pacote tecnológico e teve como objetivo homogeneizar o campo, ocultou, por muitos anos, a capacidade de organização dos agricultores familiares, retirando-lhes o poder de decisão, já que havia um atrelamento dos agricultores as grandes empresas, vinculadas a Revolução Verde, atuando a montante e a jusante da produção agrícola (KARNOPP et al., 2016).

Mas esse processo não foi aceito de forma pacífica pelos agricultores. Houve processos de resistência e busca por alternativas no decorrer desses anos, com repercussões diversas. Uma dessas alternativas é a agroindústria familiar (KARNOPP et al., 2016). O desenvolvimento rural implica a criação de novos produtos e serviços e a abertura de novos mercados abrangendo a reconfiguração dos recursos rurais. "Terra, trabalho, natureza, ecossistemas, animais, plantas, habilidades artesanais, redes e relações urbano-rural têm que ser reformatadas e recombinadas" (PLOEG et al., 2000, p. 398).

Para Wilkinson (1999) apud Mior (2003) após a abertura econômica, desregulação da economia e a integração ao Mercosul, as exigências teriam aumentado, dificultando a inserção da agricultura familiar nos mercados de commodities tradicionais. Assim, as estratégias de inserção da agricultura familiar devem se pautar na busca de oportunidades de mercado, como as de produtos orgânicos e artesanais voltadas à agroindústria familiar (MIOR, 2003).

A agroindústria familiar rural, segundo Mior (2005) é uma forma de organização da agricultura familiar em que o processo de produção de parte da produção agrícola e/ou pecuária da propriedade é feita pela família, com o objetivo de comercialização. A agroindústria familiar rural também tem outras particularidades, "tais como: a localização no meio rural; a utilização de máquinas e equipamentos e escalas menores; procedência própria da matéria-prima em sua maior parte, ou de vizinhos; processos artesanais próprios, assim como predominância da mão-de-obra familiar" (MIOR, 2005, p. 8). 
Prezotto (2002) apresenta que a agroindústria familiar contribui para a retomada dos saberes sociais das unidades de produção familiar no que se refere a produção e conservação de alimentos que, ao longo do tempo, sempre existiram nas propriedades rurais e que foram gradativamente sendo preteridas pelo modelo de modernização da agricultura.

A partir das considerações acima, o objetivo do artigo é identificar de que forma a agroindústria familiar contribui como estratégia de reprodução e fortalecimento da agricultura familiar.

Esta pesquisa se justifica pelo potencial que a agroindústria familiar possui para o desenvolvimento rural, utilizando técnicas para o manejo sustentável, além de aproveitar as oportunidades e alternativas de produção nos diversos setores da economia para manutenção da propriedade, permanência da família no campo e aumento da renda familiar.

Este artigo encontra-se estruturado, inicialmente, por essa introdução, seguida de uma revisão teórica sobre desenvolvimento rural, agricultura familiar e agroindústria familiar. Posteriormente, descreve-se a metodologia e as discussões dos resultados encontrados. E, para finalizar, as considerações finais seguidas das referências pesquisadas.

\section{Desenvolvimento Rural}

Nos últimos cinquenta anos, a noção de 'desenvolvimento' divide-se em dois momentos distintos. O primeiro ocorre após a Segunda Guerra e os anos que se seguiram, chamados de 'Trinta Gloriosos', pautados sobre a ideia de desenvolvimento. O segundo momento, a partir dos anos 1990, as consequências dos resultados da 'era do desenvolvimento', marcado pela impossibilidade de desenvolvimento (NAVARRO, 2002 apud AMBROSINI; FILIPPI, 2008).

No cenário rural, iniciou-se a Revolução Verde, uma agricultura baseada em alta tecnologia, alta concentração de insumos e produtividade crescente, criando uma racionalidade produtiva e novas formas de mercantilização, rompendo com as técnicas passadas e com a autonomia que, de certa forma, caracterizava a agricultura (NAVARRO, 2002). A partir dos anos 1980, essa concepção de desenvolvimento, baseada na industrialização, urbanização e burocratização gerou efeitos sociais desastrosos: deterioração ambiental, êxodo rural, concentração urbana (BREINTENBACH; FROEHLICH; BRANDÃO, 2009).

A problemática ambiental surge como um sintoma e um questionamento do modelo de civilização construído sobre um conjunto de elementos de racionalidade das sociedades modernas. A racionalidade capitalista fundou-se num crescente processo de racionalização instrumental e formal, que se expressa nos princípios abstratos da economia e nos padrões tecnológicos, na organização burocrática e nos aparelhos ideológicos do Estado (LEFF, 2009).

A questão ambiental leva à necessidade de limites e normas ecológicas para os processos econômicos e tecnológicos que, sujeitos à lógica do mercado, têm degradado o ambiente e a qualidade de vida. Esta consciência ambiental introduz novos princípios valorativos e forças materiais para reorientar o processo de desenvolvimento (LEFF, 2009).

De acordo com Boff (2014), o grau de sustentabilidade de uma sociedade pode ser medido pela sua capacidade de inclusão de todos os indivíduos e demais seres, em seus respectivos ambientes, garantindo-lhes os meios de sustento e vida adequados, suficientes e decentes.

Polanyi (2012), em seus estudos afirma que o desenvolvimento é um processo que ultrapassa o domínio da economia, pois engloba um conjunto de aspectos que interagem entre si (sociais, culturais, políticos, econômicos e ambientais) (RODRIGUES; SANTOS, 2017). 
Conforme Polanyi (2009) apud Plein (2016, p. 61), “[...]o mercado não é somente oferta-demanda-preço e as motivações humanas não são só materiais, mas podem ser políticas, religiosas, estéticas [...]".

Ao realizar sua crítica a economia de mercado, Polanyi $(2000 ; 2012)$ afirma que a falácia economicista, desenraizada da sociedade, causou a separação daquilo que não se pode separar, ou seja, homem, natureza e organização produtiva. "A sociedade do século XIX organizou-se de um modo que fazia com que apenas a fome e o lucro fossem motivações eficazes para o indivíduo participar da vida econômica" (POLANYI, 2012, p. 55).

Polanyi (2000) busca em sua obra demostrar a necessidade de reconstrução social através de outras forças que possam mover o sistema rumo ao equilíbrio (STIGLITZ, 2012).

Quais seriam essas outras forças ou os contramovimentos dentro do desenvolvimento rural? Atualmente, há discussões sobre desenvolvimento rural que tratam de perspectivas relacionadas a território, ruralidade, desenvolvimento local. Schneider (2009) aponta os núcleos temáticos que vêm sendo tratados por estudiosos do mundo rural, agências e organizações nacionais e internacionais:

(a) a ruralidade é heterogênea e não circunscrita às atividades agrícolas; (b) os territórios são espaços adequados para se pensar a articulação entre escalas regionais e locais e a globalização; (c) o desenvolvimento precisa levar em conta não apenas questões econômicas, tecnológicas e produtivas, mas também culturais e ambientais; (d) a mudança é um processo lento, que precisa trazer efeitos práticos como melhorar a renda e a qualidade de vida, mas também incidir sobre a mentalidade das pessoas envolvidas e ser capaz de ser assimilado pelas instituições (SCHNEIDER, 2009, p. 26).

Polanyi (2000) aponta para esses contramovimentos, como práticas diversas e heterogêneas que os agricultores familiares buscam para defender e criar autonomia e melhores condições de vida como respostas locais para problemas globais.

\section{Agricultura Familiar}

Segundo Grisa e Schneider (2015), no final da década de 80 e início da década de 90, o debate sobre agricultura familiar ganha força com a criação do Programa Nacional de Fortalecimento da Agricultura Familiar (PRONAF) em 1995, e passa a ser vista como categoria no meio rural, desencadeando a emergência de outras políticas diferenciadas de desenvolvimento rural; a criação do Ministério do Desenvolvimento Agrário (MDA) em 1999 e a criação da Secretaria da Agricultura Familiar (SAF) em 2001, que institucionalizou a dualidade da estrutura agrária e fundiária no País e a Lei da Agricultura Familiar que reconheceu a categoria social e a partir desses eventos a agricultura familiar passou a fazer parte da arena das políticas públicas.

A Lei no 11.326, também conhecida como “Lei da Agricultura Familiar", criada em 2006, considera agricultor familiar

aquele que pratica atividades no meio rural, atendendo simultaneamente, aos seguintes requisitos: I não detenha, a qualquer título, área maior do que 4 (quatro) módulos fiscais; II utilize predominantemente mão de obra da própria família nas atividades econômicas do seu estabelecimento ou empreendimento; III tenha renda familiar predominantemente originada de atividades 
econômicas vinculadas ao próprio estabelecimento ou empreendimento; IV dirija seu estabelecimento ou empreendimento com sua família (BRASIL, 2006).

Além das definições normativas e operacionais (Lei de Agricultura Familiar, entre outras), utilizadas para a construção de políticas públicas da agricultura familiar, deve-se citar as definições que abrangem a agricultura familiar não somente pelo tamanho do estabelecimento, mas também pela forma com que as pessoas cultivam e vivem nesse meio rural. Ploeg (2014) afirma que agricultura familiar é também considerada uma forma de vida.

O estabelecimento familiar faz parte da paisagem rural. Nele, pode-se trabalhar com a natureza, em vez de contrária ela, ao se valer dos processos e dos equilíbrios ecológicos (em vez de interromper) e preservar a beleza e a integridade das paisagens. Quando a agricultura familiar trabalha com a natureza, contribui localmente para a conservação da biodiversidade e para a luta contra as mudanças climáticas globais. Seu trabalho implica uma interação contínua e direta com a natureza viva - uma característica altamente valorizada pelos próprios agricultores (PLOEG, 2014, p. 10).

Para Carmo e Salles (1998) apud Grisa e Schneider (2015) a agricultura familiar tem a família como elemento básico de gestão financeira e da mão de obra disponível. Assim, avaliar a mesma apenas pelo aspecto econômico não é suficiente para entender as relações entre a organização interna da produção e comercialização em bases familiares e o mundo externo. Diferente da agricultura empresarial que tem sua produção totalmente orientada para o mercado, a produção é altamente mecanizada e a mão de obra é assalariada (GRISA; SCHNEIDER, 2015).

Abramovay (1997) define agricultura familiar, destacando seus aspectos relevantes

[...] agricultura familiar é aquela em que a gestão, a propriedade e a maior parte do trabalho vêm de indivíduos que mantêm entre si laços de sangue ou de parentesco. O importante é que estes três atributos básicos (gestão, propriedade e trabalho familiares) estão presentes em todas elas[...] (ABRAMOVAY, 1997, p. 03).

Segundo o estudo 0 estado mundial da agricultura e alimentação, 2014: Inovação na agricultura familiar, da FAO, mais de 500 milhões de fazendas familiares administram a maior parte da terra agrícola e produzem a maior parte da comida do mundo. Fazendas familiares são necessárias para garantir a segurança alimentar global, cuidar e proteger o meio ambiente natural e acabar com a pobreza, subnutrição e desnutrição. Mas esses objetivos só podem ser alcançados se a agricultura familiar se tornar muito mais produtiva e sustentável; em outras palavras, eles precisam inovar em um sistema que reconheça sua diversidade e a complexidade dos desafios que eles enfrentam (FAO, 2015).

O Brasil possui, conforme o Censo (2006) 4.900.000 estabelecimentos e deste total, 4.150 .000 (85\%) correspondem ao setor da agricultura familiar e 550.000 (12\%), ao setor patronal. Mas a agricultura familiar responde por 38\% da produção agrícola nacional, ocupa $75 \%$ da população ativa agrícola e de $25 \%$ dos financiamentos públicos destinados ao conjunto do setor (SABOURIN, 2007).

Apesar de todos os desafios e dificuldades, a agricultura familiar permanece como o modelo principal do desenvolvimento rural brasileiro e, embora possua menor proporção de terras, é mais significativa em quantidade, gerando mais trabalho e renda, além de contribuir com uma produção maior por área cultivada (ABRAMOVAY, 1997). 
Wilkinson (1999; 2000) apud Mior (2003) tem defendido em seus estudos que a agricultura familiar deve participar ativamente na agroindustrialização, uma alternativa que pode ser uma forma de fortalecer sua capacidade de reprodução social. Afirma também que há a necessidade de políticas públicas para a agroindustrialização, que abrangem desde o mercado informal até mercados de nicho, produtos orgânicos e de qualidade diferenciada (MIOR, 2003).

\section{Agroindústrias Familiares}

O cenário do sistema agroalimentar vem se modificando com a globalização, juntamente com a abertura dos mercados - incluindo a integração regional do Mercosul, criando um novo ambiente concorrencial que ameaçou diretamente a participação da agricultura familiar. Esse cenário trouxe a necessidade de aumentar a lucratividade por meio dos ganhos de escala, inclusão de insumos modernos (genéticos e químicos), novos maquinários e inovações tecnológicas, tornando-se condição básica para manutenção ou entrada nos mercados (WILKINSON, 2003).

No entanto, essa abertura de mercados e a globalização trouxe uma produção altamente industrializada, com a maioria dos produtos apresentando procedência desconhecida, qualidade indiferenciada e irresponsabilidade nas questões sociais e ambientais, gerando incerteza e desconfiança por parte dos consumidores. O estopim foi a crise sanitária que trouxe inquietação dos consumidores de todo o mundo através da vaca louca, febre aftosa, gripe aviária, salmonela, etc. Esse contexto de insegurança gerou um movimento dos consumidores na busca por alimentos mais saudáveis, de origem conhecida, com menores riscos à saúde e ao meio ambiente (BURCH; LAWRENCE, 2005).

No centro dessas transformações, passou-se a valorizar os produtos orgânicos, com denominação de origem e da agricultura familiar, associados à tradição, à natureza, ao artesanal e ao local (WILKINSON, 2003).

Essa demanda por produtos tradicionais e de origem conhecida abriu espaço a agricultura familiar através das tendências de valorização dos produtos diferenciados baseados em conhecimentos específicos, permitindo a criação de novos espaços para os produtos feitos nas agroindústrias familiares (FLEXOR, 2006).

Para Mior (2003), após os anos 1990, a agroindustrialização passou a atuar como estratégia de promoção da agricultura familiar e de desenvolvimento do espaço rural, ganhando legitimidade favorecendo o surgimento e difusão destas novas formas de organização da produção e inserção no mercado. A agroindústria familiar rural é definida por Mior (2005, p. 191), como "uma forma de organização em que a família rural produz, processa e/ou transforma parte de sua produção agrícola e/ou pecuária, visando, sobretudo, a produção de valor de troca que se realiza na comercialização".

$\mathrm{Na}$ agroindustrialização, a mão-de-obra e o know how para transformação dos produtos agrícolas, passam a ser revalorizados. O conhecimento dos métodos de processamento de alimentos, feito pelas mulheres nas propriedades, sai da cozinha da casa e passa a ser fundamental para a atividade de agroindustrialização na agricultura familiar (MIOR, 2003).

A agroindustrialização, responsável por agregar valor à produção primária, viabiliza o aumento da renda nas unidades familiares e é nesse contexto, de busca por alternativas de renda, que agricultores familiares vêm se dedicando à criação de pequenas agroindústrias (KARNOPP et al., 2016). A dinâmica dos canais de comercialização da agroindústria familiar pode ser visualizada na figura abaixo. 
Figura 1: Tipologia dos canais de comercialização construídos pelas agroindústrias familiares e seus percentuais de participação relativa

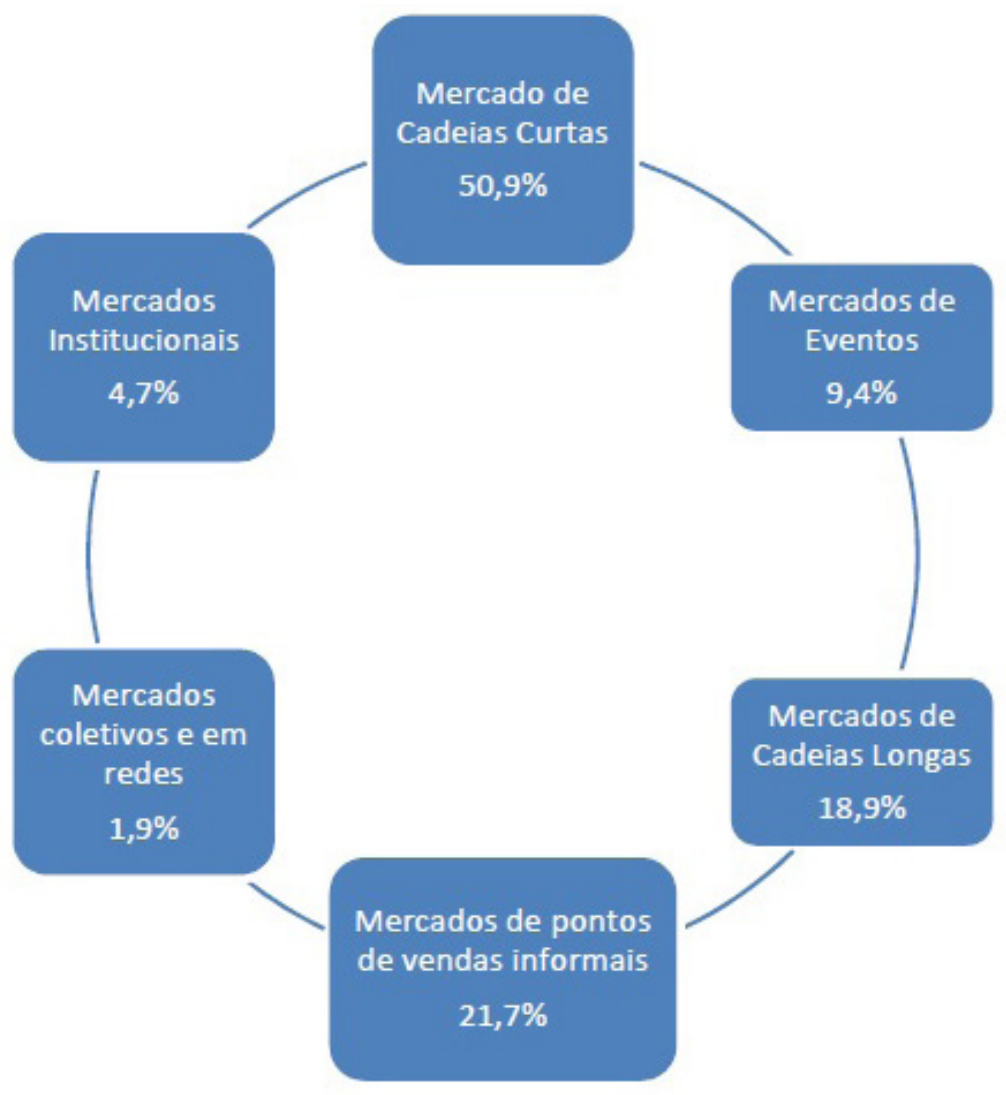

Fonte: GAZOLLA (2017).

Em relação aos canais de comercialização, os mercados institucionais que possuem 4,7\% do total comercializado, exercem três efeitos junto as agroindústrias. Em primeiro lugar, fortalecem as atividades produtivas e a economia das famílias, já que houve um aumento de produção e de renda gerada com as vendas. Em segundo lugar, estimulam a inserção de novos canais de comercialização, pois os produtores passam a interagir com as instituições públicas, consumidores, entidades que antes não faziam parte de sua rede de contatos. E por último, cria-se o fortalecimento dos circuitos locais de produção-consumo, pois esses programas aproximam produtores e consumidores (GAZOLLA, 2017).

As cadeias curtas que representam 50,9\% das vendas são os principais canais de comercialização dos alimentos das agroindústrias. As vendas ocorrem na própria agroindústria, nas ruas, locais de trabalho, entrega em residências, feiras, etc. Esses canais diretos são os principais canais utilizados pelos agricultores, pela autonomia que lhes concede, pois eles produzem e vendem a preços negociados na hora da troca (GAZOLLA, 2017).

Os canais de eventos, responsáveis por 9,4\% das vendas é composto pelas vendas em feiras, eventos, festas e exposições locais. Uma das principais características desse canal é a divulgação dos produtos, através de degustações, visualização dos alimentos e conversa com o público visitante. As cadeias longas, com 18,9\% das vendas, são responsáveis por suprir as redes de supermercados, compradores, intermediários, indústrias e atacados, que redistribuem a produção e por essa razão, são chamadas cadeias longas, já que a distância percorrida pelos produtos é maior. De forma geral, esse canal é utilizado por agroindústrias com escala maior de produção, pois os custos de logística são altos para deslocamento dos produtos (GAZOLLA, 2017). 
Os pontos de vendas formais, responsáveis por 21,7\% das vendas, são pontos de comercialização de consumo de alimentos como supermercados locais, bares, restaurantes e cantinas. Assim como os canais institucionais e as redes longas, exigem a formalização das agroindústrias para colocar seus produtos a venda. Os canais coletivos e em redes "são caracterizados por organizações sociais coletivas formando redes em torno das agroindústrias, objetivando a comercialização dos alimentos" (GAZOLLA, 2017, p. 185). Representam as cooperativas, associações grupos e feiras de produtores e são responsáveis por 4,9\% das vendas das agroindústrias (GAZOLLA, 2017).

Segundo Mior (2003), a trajetória de constituição e produção da agroindústria familiar é diferente da agroindústria convencional. A forma de produção da matéria prima processada (própria, local, natural ou agroecológica), os insumos utilizados (naturais e/ou químicos), o tipo de produção (colonial, artesanal), além dos tipos de relação com o público consumidor (relações de confiança), diferenciam a agroindústria familiar, tornando-a única. O quadro 1 traz as oportunidades, desafios e dificuldades das agroindústrias na comercialização de seus produtos.

Quadro 1: Oportunidades, desafios e dificuldades das agroindústrias familiares na construção de cadeias curtas de comercialização dos alimentos

\begin{tabular}{|c|c|c|}
\hline ATOR SOCIAL & OPORTUNIDADES & DESAFIOS E DIFICULDADES \\
\hline $\begin{array}{l}\text { Agricultores } \\
\text { familiares donos } \\
\text { de agroindústrias } \\
\text { (experiências } \\
\text { individuais e } \\
\text { coletivas). }\end{array}$ & $\begin{array}{l}\text { Obtenção de maior valor agregado pelo } \\
\text { encurtamento dos elos da cadeia produtiva; } \\
\text { Recebimento de maiores preços pelos } \\
\text { alimentos, em relação aos pagos pela GDA } \\
\text { (Grupos de Aquisições solidárias); } \\
\text { Mercados Institucionais (PAA E PNAE) } \\
\text { ajudam a ampliar cadeias curtas e vendas; } \\
\text { Possibilidade de inovar e diversificar } \\
\text { portfólio de produtos e processos } \\
\text { agroalimentares; } \\
\text { Crescente reconhecimento da importância } \\
\text { pelo Estado em diferentes níveis } \\
\text { institucionais; } \\
\text { Os alimentos em muitos casos são } \\
\text { artesanais, étnicos orgânicos, da agricultura } \\
\text { familiar, agroecológicos, etc., sendo vistos } \\
\text { como diferenciados em relação a GDA; } \\
\text { Vendas baseiam-se em relações de } \\
\text { proximidade social, interconhecimento } \\
\text { e confiança mútua dos atores } \\
\text { (agricultores-consumidores); } \\
\text { Experiências individuais baseiam-se em } \\
\text { economias de escopo e as coletivas ganham } \\
\text { escala mínima através do associativismo/ } \\
\text { cooperativismo. }\end{array}$ & $\begin{array}{l}\text { Altos índices de experiências na } \\
\text { informalidade institucional, em vários } \\
\text { níveis territoriais e dimensões (sanitário, } \\
\text { ambiental, jurídico, fiscal, etc.); } \\
\text { Manter o fornecimento de alguns } \\
\text { alimentos durante o ano todo, devido à } \\
\text { sazonalidade da produção; } \\
\text { Dificuldades de gerir toda a cadeira } \\
\text { de produção (produção de matérias- } \\
\text { primas - processamento - mercados - } \\
\text { administração do negócio); } \\
\text { Poucos membros familiares na unidade de } \\
\text { produção (há falta de força de trabalho); } \\
\text { Necessidade de readequãão de alguns } \\
\text { alimentos para acesso aos mercados } \\
\text { institucionais (mudança de tamanho em } \\
\text { relação a embalagem, na embalagem, } \\
\text { formato do alimento, características } \\
\text { específicas); } \\
\text { As políticas públicas e programas atuam } \\
\text { muito focalizadas no fornecimento } \\
\text { de crédito rural e estruturas de } \\
\text { processamento; } \\
\text { Pouco apoio institucional a nível local e } \\
\text { dificuldades de implementar os sistemas } \\
\text { de Inspeção Municipal (siM); } \\
\text { Dificuldades de expandir redes de } \\
\text { comercialização e consumo locais, } \\
\text { nos pequenos municípios (scale up das } \\
\text { experiências). }\end{array}$ \\
\hline
\end{tabular}

Fonte: GAZOLLA (2017). 
As agroindústrias familiares podem ser vistas como um processo de reconfiguração de recursos promovido pela agricultura familiar, em conjunto com suas organizações associativas e com o apoio do poder público. Da transformação de uma matéria-prima ou um produto conservado para a subsistência da família rural, esse produto processado passa a ser visto como opção de produto comercial com um valor de troca e, portanto, como fonte de renda da unidade de produção familiar. O fortalecimento da agroindústria familiar dependerá da "capacidade dos agricultores em responder ao desafio de manter e aprimorar esta forma de organização e, ao mesmo tempo, fortalecer a inserção regional em novas cadeias produtivas" (KARNOPP et al., 2016, p. 681).

\section{Estudos Anteriores}

$\mathrm{Na}$ área acadêmica, a agroindústria familiar rural vem ganhando espaço e diferentes estudos já realizados apontam, de forma positiva, para as transformações promovidas pela atividade para o fortalecimento da agricultura familiar.

Wesz Jr., Trentin e Filippi (2006) em seu estudo, fizeram uma análise conceitual sobre as agroindústrias familiares, retratando de forma objetiva a delimitação das atribuições desse conceito. Em seguida mostraram, detalhadamente, a importância e representatividade das agroindústrias rurais para as estratégias de desenvolvimento, focando para a perspectiva rural e territorial. Identificaram que a agroindústria familiar se constitui em uma importante ferramenta para o meio rural, primeiro porque contribui, e muito, para um desenvolvimento sustentável dos atores envolvidos. E segundo, por encaixar-se perfeitamente em inúmeras realidades podendo, dessa forma, contribuir para os territórios de forma multidimensional e diversificada. Além de criar várias identidades, não ficando dependente de apenas de um setor agropecuário ou, até mesmo, de uma monocultura como é o caso de muitas regiões.

Mior et al. (2014), fizeram um estudo no qual identificaram que em diferentes regiões de Santa Catarina os agricultores familiares buscam formas de ampliar as suas possibilidades de reprodução social no espaço rural, dentre as quais estão a constituição de empreendimentos de agregação de valor e de redes de cooperação visando sua inserção no mercado. A partir de duas pesquisas, uma realizada em 2010 e outra iniciada em 2013, este artigo analisou este processo de transformação no Sul Catarinense. Destacaram como inovações as agroindústrias familiares e as cooperativas descentralizadas que possibilitam novas formas de inserção nos mercados e ampliam as condições de autonomia e geração de valor agregado pelos agricultores familiares e suas organizações.

Strate e Conterato (2018) analisaram em seu estudo como os arranjos produtivos locais podem fomentar a diversificação da agricultura familiar, realocando a produção de alimentos através das cadeias curtas, estimulando a heterogeneidade e promovendo o desenvolvimento rural. A pesquisa foi realizada a partir do Arranjo Produtivo Agroindústria Familiar, estrutura de governança que impulsiona a instalação, regularização e associativismo de agroindústrias no Vale do Taquari/RS. A metodologia utilizada foi a análise documental e entrevistas com gestores do APL Agroindústria e proprietários de agroindústrias integrantes do APL. Como resultado puderam observar que as políticas públicas de fomento para a implementação e fortalecimento dos APL's e incentivo ao turismo constituem-se estratégias que podem fortalecer a agricultura familiar, promovendo a construção e o acesso a novos mercados, a criação e o desenvolvimento de novos produtos, promovendo a sucessão rural, diversificando as atividades produtivas, gerando renda através de novos arranjos sociais e estruturas de governança horizontalizadas. 


\section{Metodologia}

O delineamento da pesquisa se constituiu pela pesquisa bibliográfica. Conforme Martins e Theóphilo (2016, p. 52)

trata-se de estratégia de pesquisa necessária para a condução de qualquer pesquisa científica. Uma pesquisa bibliográfica procura explicar e discutir um assunto, tema ou problema com base em referências publicadas em livros, periódicos, revistas, jornais, sites, anais de congressos etc.

O processo desenvolvido para o artigo em questão apresenta-se por meio de uma revisão de literatura, efetuando um levantamento de informações obtidas em pesquisas já realizadas, destacando conceitos, resultados e conclusões importantes para o entendimento e aprimoramento da temática sobre agroindústria familiar.

A revisão da literatura promove o levantamento acerca do que já se conhece em relação ao assunto que está sendo pesquisado. Possibilita, portanto, identificar lacunas no conhecimento existente e, consequentemente, orientar a pesquisa com o propósito de preenchê-las (GIL, 2019, p.73).

A abordagem é qualitativa, pois não descreve os resultados de forma numérica ou estatística, como na pesquisa quantitativa. A pesquisa qualitativa segundo Richardson $(1999$, p. 90) "pode ser caracterizada como a tentativa de uma compreensão detalhada dos significados e características situacionais apresentadas pelos entrevistados em lugar da produção de medidas quantitativas de características ou comportamentos."

\section{Agroindústria familiar como alternativa de reprodução da agricultura familiar}

A tabela 1 apresenta um primeiro conjunto de informações referentes a diferentes dinâmicas macrorregionais da agroindústria rural. A agregação de valor é um dos primeiros aspectos analisados na dinâmica da agroindústria familiar.

Tabela 1: Número total de estabelecimentos agropecuários com agroindústria rural, valor total da venda e valor agregado total dos produtos agroindustriais, segundo as grandes regiões brasileiras - 2006

\begin{tabular}{l|l|l|l|l}
\hline REGIÃO & № AGROINDÚSTRIAS (A) & $\begin{array}{l}\text { VALOR TOTAL DA } \\
\text { VENDA (B) }\end{array}$ & $\begin{array}{l}\text { VALOR AGREGADO } \\
\text { TOTAL (C) }\end{array}$ & $\begin{array}{l}\text { C/B } \\
\%\end{array}$ \\
\hline NORTE & 82.761 & 535.996 .040 & 78.132 .396 & 14,6 \\
\hline NORDESTE & 281.083 & 1.159 .930 .140 & 161.606 .313 & 13,9 \\
\hline SUDESTE & 60.794 & 797.321 .947 & 88.970 .316 & 11,2 \\
\hline SUL & 133.372 & 270.099 .996 & 31.280 .336 & 11,6 \\
\hline CENTRO-OESTE & 13.633 & 271.512 .929 & 16.339 .296 & 6,0 \\
\hline BRASIL & 571.643 & 3.034 .861 .052 & 376.328 .656 & 12,4 \\
\hline
\end{tabular}

FONTE: IBGE - Censo Agropecuário (2006), adaptado de Gazolla, Nierdele e Waquil, (2012).

A partir desses dados do Censo Agropecuário (IBGE, 2006), dispostos na tabela 1, identificou-se que o valor agregado pela agroindústria rural representa $12,4 \%$ do montante do valor comercializado. 
A agregação de valor é frequentemente considerada o principal mecanismo propulsor de desenvolvimento econômico associado às agroindústrias rurais. Os produtos das agroindústrias de base familiar trazem consigo um valor agregado diferente dos produtos tradicionais industrializados como por exemplo a produção artesanal, tradição, saber-fazer, origem, sabor, que permite aos produtores obter um valor diferenciado nos mercados. Esse "valor agregado" derivada de particularidades sociais, ambientais e culturais que estão sendo crescentemente revalorizadas pelos consumidores (TOUZARD, 2010 apud GAZOLLA; NIERDELE; WAQUIL, 2012).

Além dos dados acima, outros dados censitários revelam que as agroindústrias da agricultura familiar respondem pela maior parcela dos valores agregados à produção associados à transformação dos alimentos. Esse segmento social é responsável por 78,40\% da agregação de valor, enquanto as agroindústrias da agricultura não familiar abarcam um percentual de 21,60\%. Isso ratifica o peso mais expressivo dos estabelecimentos familiares neste tipo de estratégia de produção agroalimentar, como já mencionado por outros estudos (MIOR, 2005; WILKINSON, 2008; GAZOLLA; PELEGRINI, 2011 apud GAZOLLA; NIERDELE; WAQUIL, 2012).

A agregação de valor na agroindústria rural também está diretamente associada ao uso de insumos produtivos, o que demonstra o potencial da atividade na redução da dependência a recursos e agentes externos. O uso de matéria prima própria nos estabelecimentos da agricultura familiar é

igual ou superior a $75 \%$, alcançando proporções equivalentes a $91 \%$ para a produção de rapadura, $90 \%$ para a farinha de mandioca, $89 \%$ para queijos e $88 \%$ para tapioca. E mesmo quando a matéria prima é comprada, geralmente isso ocorre em circuitos de proximidade que alimentam relações comunitárias (WAQUIL et al., 2014, p. 65).

Outro aspecto que pode ser destacado na dinâmica da agroindústria familiar é a geração de emprego. É uma das principais geradoras de empregos diretos e indiretos por unidade de capital investido. Conforme dados do BNDS e do IBGE, os empreendimentos agropecuários e agroindustriais chegam a gerar de 118 a 182 empregos, para cada milhão de dólar investido, e se comparado ao setor comercial, que emprega bastante mão de obra, a agroindústria representa cerca de $80 \%$ a mais (TRENTIN, 2001).

Considerando a geração de renda e melhor qualidade de vida para os atores desse processo, a agroindustrialização rural tem como contribuição, a permanência do agricultor no campo, além de fomentar a economia local, [...]pela relação de proximidade que existe tanto na contratação de mão-de-obra como no fornecimento da matéria prima pelos vizinhos, bem como, na comercialização dos produtos, que se realiza numa escala estreitamente regionalizada [...] (WESZ JR., 2006, p. 25).

Quanto a produtividade, um estudo do MDA mostra que enquanto uma cultura tradicional do território, como o milho, a soja, o trigo etc., pode chegar a gerar, no máximo, $\mathrm{R} \$ 400,00$ / ha, as agroindústrias familiares de frutas e de cana-de-açúcar podem chegar até R\$4.000,00/ ha (PELEGRINI; GAZOLLA, 2009).

No final da década de 90, surgiu uma linha de crédito voltada ao apoio das agroindústrias familiares decorrente de uma demanda que existia no Brasil, em especial no Sul do País. Inicialmente chamada de Pronaf-Agregar, passou em 2003 para a denominação de Pronaf-Agroindústria, até a inclusão dessa modalidade no Programa Mais Alimentos (WESZ JR., 2010). 
Além dessa linha de crédito federal, foram implementadas algumas iniciativas na escala estadual destinadas ao apoio das agroindústrias familiares, merecendo destaque o Programa de Verticalização da Pequena Produção Agrícola do Distrito Federal - Prove/DF (1995 a 1998), o Programa de Verticalização da Pequena Produção Agropecuária - Prove-Pantanal/MS (1999 a 2002), o Programa de Desenvolvimento da Agricultura Familiar Catarinense pela Verticalização da Produção - Desenvolver/SC (1999 a 2001), o Programa da Agroindústria Familiar - PAF/RS (1999 a 2002) e o Programa Fábrica do Agricultor - PR (1999 a 2010) (WESZ JR., 2010, p. 569).

No quadro 2 apresenta-se várias vantagens na adoção do modelo de agroindustrialização familiar em comparação a tradicional.

De um modo geral, os municípios agrícolas necessitam da agroindústria familiar para a sustentabilidade socioeconômica e para o desenvolvimento regional. Pois essas além de distribuírem os investimentos, pulverizam as ações comerciais entre atores que até então estavam fora deste processo (PADILHA, FERREIRA; TRENTIN, 2005, p.8).

Quadro 2: Quadro comparativo das agroindústrias

\begin{tabular}{|l|l|}
\hline Agroindústria Tradicional & Agroindústria Familiar \\
\hline $\begin{array}{l}\text { 1) Processo de agregação de valor baseado em } \\
\text { grandes unidades agroindustriais. }\end{array}$ & $\begin{array}{l}\text { 1) Agregação de valor centrado nas micro e } \\
\text { pequenas agroindústrias familiares. }\end{array}$ \\
\hline $\begin{array}{l}\text { 2) Modelo centralizado em uma ou poucas } \\
\text { agroindústrias por ramos. }\end{array}$ & $\begin{array}{l}\text { 2) Modelo descentralizado, com várias micro } \\
\text { e pequenas agroindústrias por ramo em várias } \\
\text { regiões. }\end{array}$ \\
\hline $\begin{array}{l}\text { 3) Concentração industrial nas regiões Sudeste e Sul } \\
\text { do Brasil. }\end{array}$ & $\begin{array}{l}\text { 3) Desconcentração demográfica prioriza pequenas e } \\
\text { médias cidades (Comunidades e Distritos Rurais). }\end{array}$ \\
\hline $\begin{array}{l}\text { 4) Indústria localizada nos médios e grandes centros } \\
\text { urbanos (Grande SP/RJ/BH/Região Metropolitana } \\
\text { de Curitiba e Porto Alegre) ou em pólos regionais } \\
\text { (Chapecó/SC, Caxias do Sul/RS, Cascavel/PR). }\end{array}$ & $\begin{array}{l}\text { 4) Agroindústrias descentralizadas (difusas) em } \\
\text { pequenas cidades, em comunidades locais. }\end{array}$ \\
\hline 5) Trabalho exclusivamente assalariado. & 5) Trabalho majoritariamente familiar e associativo. \\
\hline $\begin{array}{l}\text { 6) Matéria-prima é toda comprada (não } \\
\text { necessariamente na região de localização da } \\
\text { agroindústria). }\end{array}$ & 6) Matéria prima é própria/local (mínimo 80\%). \\
\hline $\begin{array}{l}\text { 7) Estratégia de ganho de escala através da } \\
\text { verticalização da produção via contratos de } \\
\text { integração. }\end{array}$ & $\begin{array}{l}\text { 7) Estratégia de ganho de escala, através de } \\
\text { associação em rede de várias categorias. }\end{array}$ \\
\hline $\begin{array}{l}\text { 8) Estimula a competição entre os produtores, } \\
\text { através da especialização e seleção. }\end{array}$ & $\begin{array}{l}\text { 8) Estimula a cooperação entre produtores com } \\
\text { manutenção da diversidade de produtos. }\end{array}$ \\
\hline $\begin{array}{l}\text { 9) Produção em massa de produtos homogêneos e } \\
\text { anônimos. }\end{array}$ & $\begin{array}{l}\text { 9) Produção de produtos diferenciados e de origem } \\
\text { conhecida. }\end{array}$ \\
\hline $\begin{array}{l}\text { 10) Grande inversão de capital por emprego. } \\
\text { posto de trabalho gerado. }\end{array}$ \\
\hline 11) Altos custos de transportes. & $\begin{array}{l}\text { 10) Baixa e média inverãa de capital para cada } \\
\text { 11) Transportes limitados (regional). }\end{array}$ \\
\hline
\end{tabular}


Conclusão

\begin{tabular}{|c|c|}
\hline Agroindústria Tradicional & Agroindústria Familiar \\
\hline $\begin{array}{l}\text { 12) Uniformização crescente da produção e consumo } \\
\text { alimentar (padrão ditado pela cultura dos Estados } \\
\text { Unidos); Fast Food, (Mac Donald's) Pizza Hutt, Corn } \\
\text { Flake's (Kellog's), etc. }\end{array}$ & $\begin{array}{l}\text { 12) Cultura alimentar local e regional, como valor a } \\
\text { ser reforçado e preservado. }\end{array}$ \\
\hline $\begin{array}{l}\text { 13) Crescente internacionalização das agroindústrias } \\
\text { (em função das fusões e aquisições por empresas } \\
\text { multinacionais). }\end{array}$ & $\begin{array}{l}\text { 13) Participação minoritária da capital internacional } \\
\text { (raramente se observa o capital internacional } \\
\text { participando desses empreendimentos). }\end{array}$ \\
\hline $\begin{array}{l}\text { 14) Separação do rural/urbano, com acentuado } \\
\text { declínio das áreas rurais. }\end{array}$ & $\begin{array}{l}\text { 14) Integração "continum" rural/urbano, com } \\
\text { revalorização das áreas rurais. }\end{array}$ \\
\hline 15) Miséria, favelas, violência, prostituição. & $\begin{array}{l}\text { 15) Padrão mínimo de desigualdade social } \\
\text { econômica. }\end{array}$ \\
\hline $\begin{array}{l}\text { 16) Presença de famintos ( } 31 \text { milhões de brasileiros) } \\
\text { e, de outro lado, excesso e a má alimentação, } \\
\text { obesidade, câncer, má formação, etc. }\end{array}$ & $\begin{array}{l}\text { 16) Readequação de renda e acesso a políticas } \\
\text { públicas. }\end{array}$ \\
\hline $\begin{array}{l}\text { 17) Poluição: afluentes industriais e dejetos de } \\
\text { animais. Destruição do meio ambiente. }\end{array}$ & $\begin{array}{l}\text { 17)Preservação e recuperação de mananciais } \\
\text { hídricos. }\end{array}$ \\
\hline $\begin{array}{l}\text { 18) Ênfase na agricultura industrial (monocultura, } \\
\text { grandes áreas; altos usos de insumos agropecuários). }\end{array}$ & $\begin{array}{l}\text { 18) Ênfase na Agricultura Familiar diversificada, } \\
\text { com utilização da agroecologia e princípios da } \\
\text { cooperação e solidariedade. }\end{array}$ \\
\hline $\begin{array}{l}\text { 19) Modelo "ideal" de agricultura, centrado no } \\
\text { agricultor (tipo patronal), grandes extensões de } \\
\text { terra, assalariamento do trabalho. Acesso ao crédito } \\
\text { facilitado; pesquisa/ ensino/ extensão/ direcionado } \\
\text { a ele. }\end{array}$ & $\begin{array}{l}\text { 19) Direcionamento das políticas públicas à } \\
\text { agricultura familiar (educação / crédito / saúde/ } \\
\text { etc.). }\end{array}$ \\
\hline $\begin{array}{l}\text { 20) Concentração da propriedade, da riqueza e } \\
\text { exploração do trabalho. }\end{array}$ & $\begin{array}{l}\text { 20) Desconcentração da propriedade (Reforma } \\
\text { Agrária) e distribuição de renda. }\end{array}$ \\
\hline 21) Êxodo Rural & $\begin{array}{l}\text { 21) Êxodo urbano/crescimento das médias e } \\
\text { pequenas propriedades }\end{array}$ \\
\hline 22) Sistema individual & $\begin{array}{l}\text { 22) Formação de associações regionais, rede de } \\
\text { cooperação e pactos. }\end{array}$ \\
\hline
\end{tabular}

Fonte: PROJETO TERRA SOLIDÁRIA - ESCOLA SUL/CUT apud Padilha, Ferreira e Trentin, 2005.

O quadro 2 que compara a agroindústria tradicional com a agroindústria familiar, identifica que a agroindústria familiar passa a gerar renda e trabalho para os componentes familiares, proporcionando sustentabilidade socioeconômica. A sustentabilidade ambiental também é um aspecto das agroindústrias, como por exemplo, o sistema de produção de energia pela queima do gás metano (biodigestor) produzido pelo esterco suíno. É um sistema de produção de energia limpa. Também exerce um papel fundamental na mitigação do êxodo rural e da desigualdade social do campo e das cidades. Em relação a comercialização, as agroindústrias familiares adotam uma rota diferente das grandes agroindústrias processadoras de commodities. Elas criam o mercado para seus produtos em nível local utilizando-se dos laços sociais, de amizade e de parentesco (WESZ JR., 2009).

As agroindústrias também proporcionam a valorização e preservação dos hábitos culturais, estímulo da proximidade social (produtor-consumidor), valorização das especificidades locais e 
alteração nas relações de gênero, uma vez que as mulheres passam a ter um papel de crescente importância nas decisões acerca da gestão do empreendimento (WESZ JR. et al., 2006).

\section{Considerações finais}

Conforme destaca MIOR (2010), o desenvolvimento da agroindústria familiar tem desdobramentos em todos os âmbitos da unidade familiar, na produção, comercialização, na diversificação econômica regional e no fortalecimento de sistemas agroecológicos de produção, entre outros aspectos.

A agroindústria familiar é uma estratégia de reprodução social importantíssima da agricultura familiar, do ponto de vista da geração de renda, de empregos e manutenção do homem nos espaços rurais, e deve ser um dos "pilares" em que deve se assentar qualquer programa ou projeto de desenvolvimento rural para este setor social a nível local ou territorial (PELEGRINI; GAZOLLA, 2009). Ela pode ser considerada um contramovimento da agricultura familiar na busca por sobrevivência centrada em outras formas de relações econômicas mais justas e coerentes para produtores e consumidores, se firmando como uma estratégia de reprodução e fortalecimento da agricultura familiar.

\section{Referências}

ABRAMOVAY, R. Uma nova extensão rural para a agricultura familiar. In: SEMINÁRIO NACIONAL DE ASSISTÊNCIA TÉCNICA E EXTENSÃO RURAL, 1., 1997, Brasília. Anais do Seminário Nacional de Ater. Brasília: PNUD, 1997.

AMBROSINI, L. B.; FILIPPI, E. E. Da era do desenvolvimento ao desenvolvimento rural: sistemas produtivos localizados sob a perspectiva de Karl Polanyi. REDES, v. 13, n. 3, p. 121-139, 2008.

BRASIL, Lei $n^{\circ}$ 11.326, de 24 de julho de 2006. Estabelece as diretrizes para a formulação da Política Nacional da Agricultura Familiar e Empreendimentos Familiares Rurais. Diário Oficial da República Federativa do Brasil, Poder Executivo, Brasília, DF, 2006.

BREITENBACH, R.; FROEHLICH, J. M.; BRANDÃO, J. B. Estratégia emergencial reativa de desenvolvimento local: Mobilização social para intensificação da produção leiteira. Revista desenvolvimento em questão, Editora Unijuí, ano 7, n. 13, p. 129-156, jan./jun. 2009.

BOFF, L. Sustentabilidade: O que é - O que não é? Rio de Janeiro: Editora Vozes, 2014.

BURCH, D.; LAWRENCE, G. Supermarket Own Brands, Supply Chains and the Transformation of the Agri-food System. International Journal of Sociology of Agriculture and Food, v. 13, n. 1, p. 1-19, jul. 2005.

FAO - Organização das Nações Unidas para Alimentação e Agricultura - O estado mundial da agricultura e alimentação, 2014: Inovação na agricultura familiar. Roma: FAO, 2015. Disponível em: <http://www.fao. org/3/a-i4040s.pdf>. Acesso em: 25 mai. 2019.

FLEXOR, G. A. Globalização do Sistema Agroalimentar e seus desafios para o Brasil. Economia Ensaios, Uberlândia, v. 21 e 21, n. 2 e 1, p. 63-95, 2006.

GAZOLLA, M. Cadeias Curtas agroalimentares na agroindústria familiar: dinâmicas e atores sociais envolvidos. In: GAZOLLA, M.; SCHNEIDER, S. (Org). Cadeias curtas e redes agroalimentares

alternativas: negócios e mercados da agricultura familiar. Porto Alegre: Editora UFRGS, 2017. p.175-194. 
GAZOLLA M.; NIEDERLE, P. A.; WAQUIL, P. D. Agregação de Valor nas Agroindústrias Rurais: uma análise com base nos dados do Censo Agropecuário. Revista Paranaense de Desenvolvimento, Curitiba, n.122, p. 241-262, jan./jun. 2012.

GIL, A. C. Métodos e Técnicas de Pesquisa Social. 7 ed. São Paulo: Atlas, 2019.

GRISA, C.; SCHNEIDER, S. Políticas públicas de desenvolvimento rural no Brasil. Porto Alegre: Editora da UFRGS, 2015.624 p.

INSTITUTO BRASILEIRO DE GEOGRAFIA E ESTATÍSTICA. Censo Agropecuário 2006: agricultura familiar. Rio de Janeiro: IBGE, 2009. 1 CD-ROM.

KARNOPP, E.; VOGT, O. P.; BERNARDY, R. J.; ETGES, V. E. Agroindústrias familiares no sul do brasil: o território na perspectiva do desenvolvimento. Revista de Desenvolvimento Econômico, Salvador, Ano XVIII, v. 2, n. 34, p. 666-684, ago. 2016.

LEFF, E. Ecologia, capital e cultura: a territorialização da racionalidade ambiental. Rio de janeiro: Editora Vozes, 2009.

MARTINS, G. de A.; THEÓPHILO, R. Metodologia da Investigação Científica para Ciências Sociais Aplicadas. 3 ed. São Paulo: Atlas, 2016.

MIOR, L. C. Agricultores familiares, agroindústrias e território: a dinâmica das redes de desenvolvimento rural no Oeste Catarinense. 2003. 316 f. Tese (Doutorado Interdisciplinar em Ciências Humanas) - Centro de Filosofia e Ciências Humanas, Universidade Federal de Santa Catarina, Florianópolis, 2003.

MIOR, L. C. Agricultores familiares, agroindústrias e redes de desenvolvimento rural. Chapecó: Argos, 2005. $338 \mathrm{p}$.

MIOR, L. C. Agricultura familiar, agroindústria e desenvolvimento territorial. 2010. Disponível em: $<$ http://nmd.ufsc.br/files/2011/05/Mior_Agricultura-familiar_agroindustria_e_desenvolvimento_ territorial.pdf>. Acesso em: 15 abr. 2019.

MIOR, L. C.; FERRARI, D. L.; MARCONDES, T.; REITER, J. M. W.; ARAÚJO, L. A. Inovações organizacionais da agricultura familiar: as agroindústrias e cooperativas descentralizadas no sul catarinense. In: CONGRESSO SOBER, 52., 2014, Goiânia. Anais do 52 SOBER. Goiânia - GO: SOBER, 2014.

NAVARRO, Z. Desenvolvimento rural no Brasil: os limites do passado e os caminhos do futuro. Revista Estudos Avançados. São Paulo, v.15, n. 43, 2001.

PADILHA, P. R. P.; FERREIRA, A. M. M.; TRENTIN, I. C. L. Viabilidade da agroindústria familiar orgânica. XLIII CONGRESSO SOBER, 43., 2005, Ribeirão Preto. Anais do 43º SOBER. Ribeirão Preto: SOBER, 2005.

PELEGRINI, G.; GAZOLLA, M. A agroindustrialização como estratégia de reprodução social da agricultura familiar. Estud. Soc. e Agric., Rio de Janeiro, v. 17, n. 2, p. 332-378, 2009.

PLEIN, C. Desenvolvimento, mercados e agricultura familiar: uma abordagem institucional da pobreza rural. 1 ed. Curitiba, PR: CRV, 2016.

PLOEG, J. D. V. D.; RENTING, H.; BRUNORI, G; et al. Rural development: from practices and policies towards theory. Sociologia Ruralis, v. 40, n. 4, p. 391-408, Oct. 2000.

PLOEG, J. D. V. D. Dez qualidades da agricultura familiar. Cadernos de Debate. Revista Agriculturas: experiências em agroecologia, n. 1, fev. 2014. 
POLANYI, K. A grande transformação: as origens de nossa época. Karl Polanyi. Tradução de Fanny Wrabel. 2. Ed. Rio de Janeiro: Elsevier, 2000.

POLANYI, K. A Subsistência do Homem e Ensaios Correlatos. Rio de Janeiro: Contraponto, 2012 (1ª. ed. inglês: 2012).

PREZOTTO, L. L. Uma concepção de agroindústria rural de pequeno porte. Revista de Ciências Humanas, Florianópolis, n. 31, p. 133-154, abr. 2002.

RICHARDSON, R. J. Pesquisa social: métodos e técnicas. 3. ed. São Paulo: Atlas, 1999.

RODRIGUES, W.; SANTOS, N. S. Karl Polanyi e o desenvolvimento econômico: um novo olhar sobre o regional/local? Revista de Desenvolvimento Econômico, Salvador, Ano XIX, v. 1, n. 36, p. 168-190, 2017.

STRATE, M. F.; CONTERATO, M. A. Agroindustrialização e arranjos produtivos locais como estratégia de diversificar e fortalecer a agricultura familiar no RS. Guaju, Matinhos, v. 4, n. 2, p. 48-62, jul./dez. 2018.

SABOURIN, E. Que política pública para a agricultura familiar no segundo governo Lula? Sociedade e Estado, Brasília, v. 22, n. 3, p. 715-751, set./dez. 2007.

SCHNEIDER, S. Ciências sociais, ruralidade e territórios: em busca de novas referências para pensar o desenvolvimento. CAMPO-TERRITÓRIO: Revista de geografia agrária, v. 4, n. 7, p. 24-62, fev. 2009.

STIGLITZ, J. Prefácio. In: POLANYI, K. (Ed.). A Grande Transformação: as origens políticas e económicas do nosso tempo. Lisboa: Edição 70. 2012. p. 9-37.

TRENTIN, I. C. L. O Pró-Rural 2000 como Política Pública de Combate à Pobreza Rural, 2001, 141 f. Dissertação (Mestrado em Desenvolvimento Rural) - Universidade Federal do Rio Grande do Sul, Porto Alegre, 2001.

WESZ JR. V. J. Política pública de agroindustrialização na agricultura familiar: uma análise do PronafAgroindústria. Rev. Econ. Sociol. Rural, Piracicaba, v. 48, n. 4, p. 567-596, out./dez. 2010.

WESZ JR. V. J. As políticas públicas de agroindustrialização na agricultura familiar: análise e avaliação da experiência brasileira, 2009, 236 f. Dissertação (Mestrado em Ciências Sociais em Desenvolvimento, Agricultura e Sociedade) - Instituto de Ciências Humanas e Sociais, Universidade Federal Rural do Rio de Janeiro, Rio de Janeiro, 2009.

WESZ JR. V. J. O perfil e a configuração estrutural das propriedades com agroindústrias familiares em nove municípios do noroeste gaúcho. Monografia pelo Cursos de Desenvolvimento Rural e Gestão Agroindustrial, São Luiz Gonzaga: UFGRS, 2006.

WESZ JR. V. J.; TRENTIN I. C. L.; FILIPPI, E. E. A importância da agroindustrialização nas estratégias de reprodução das famílias rurais. CONGRESSO DA SOBER, 44., 2006, Fortaleza. Anais do $44^{\circ}$ SOBER, Fortaleza: SOBER, 2006.

WAQUIL, P. D.; BASTIAN, L.; AMIN, M. C.; GAZOLLA, M. Agroindústrias Rurais familiares e não familiares: uma análise comparativa. REDES, Santa Cruz do Sul, v. 19, n. 3, p. 51-73, set./dez. 2014.

WILKINSON, J. A pequena produção e sua relação com os sistemas de distribuição. Campinas: UNICAMP, 2003. 